\title{
QuickSubmit til OJS 3.2
}

Denne vejledning er specielt relevant, når man via QuickSubmit skal publicere artikler, hvis oprindelige publiceringsår ikke er det samme som indeværende år. ${ }^{1}$

I QuickSubmit findes et felt, hvor man skal indskrive tidspunktet for, hvornår den pågældende artikel først blev publiceret. Denne oplysning blev tidligere overført til de data, der var tilknyttet artiklens metadata i det nummer, som artiklen senere blev lagt ind under. I OJS 3.2 kommer disse oplysninger ikke med over.

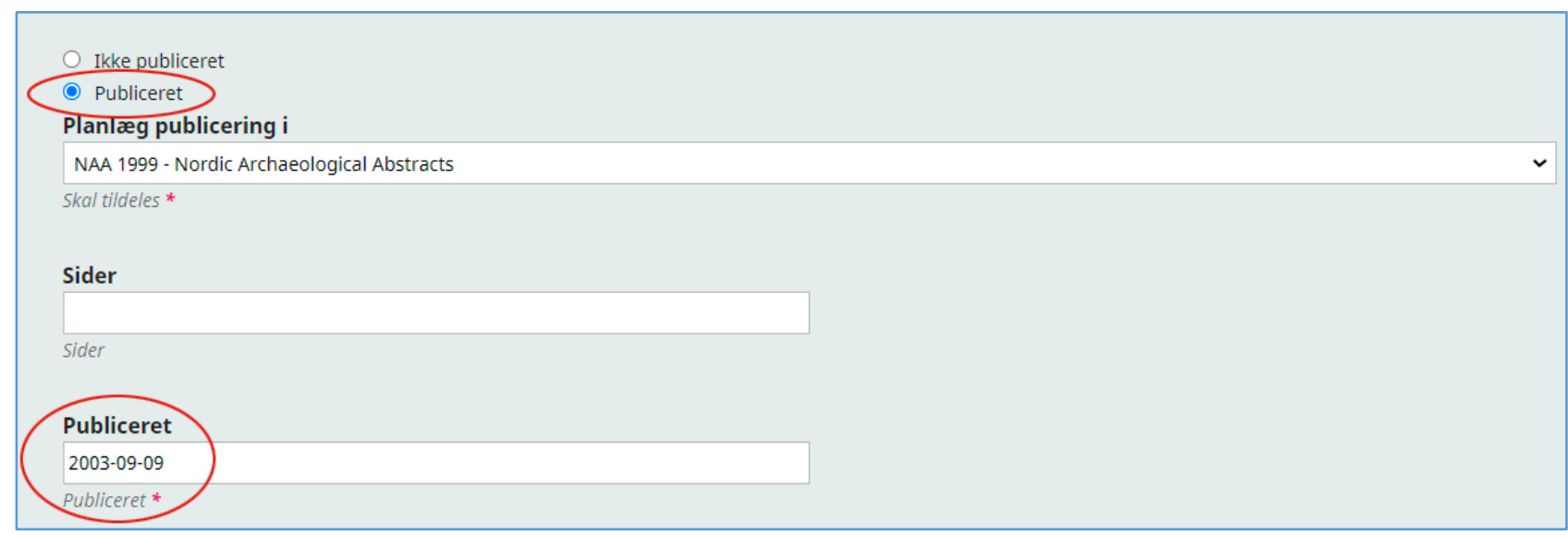

Her følger en detaljeret gennemgang af, hvordan du bruger QuickSubmit, når du publicerer "gamle" artikler.

Vælg linket 'Værktøjer' i venstre sidemenu, dernæst 'Importér/Eksportér' samt 'QuickSubmit-plugin'

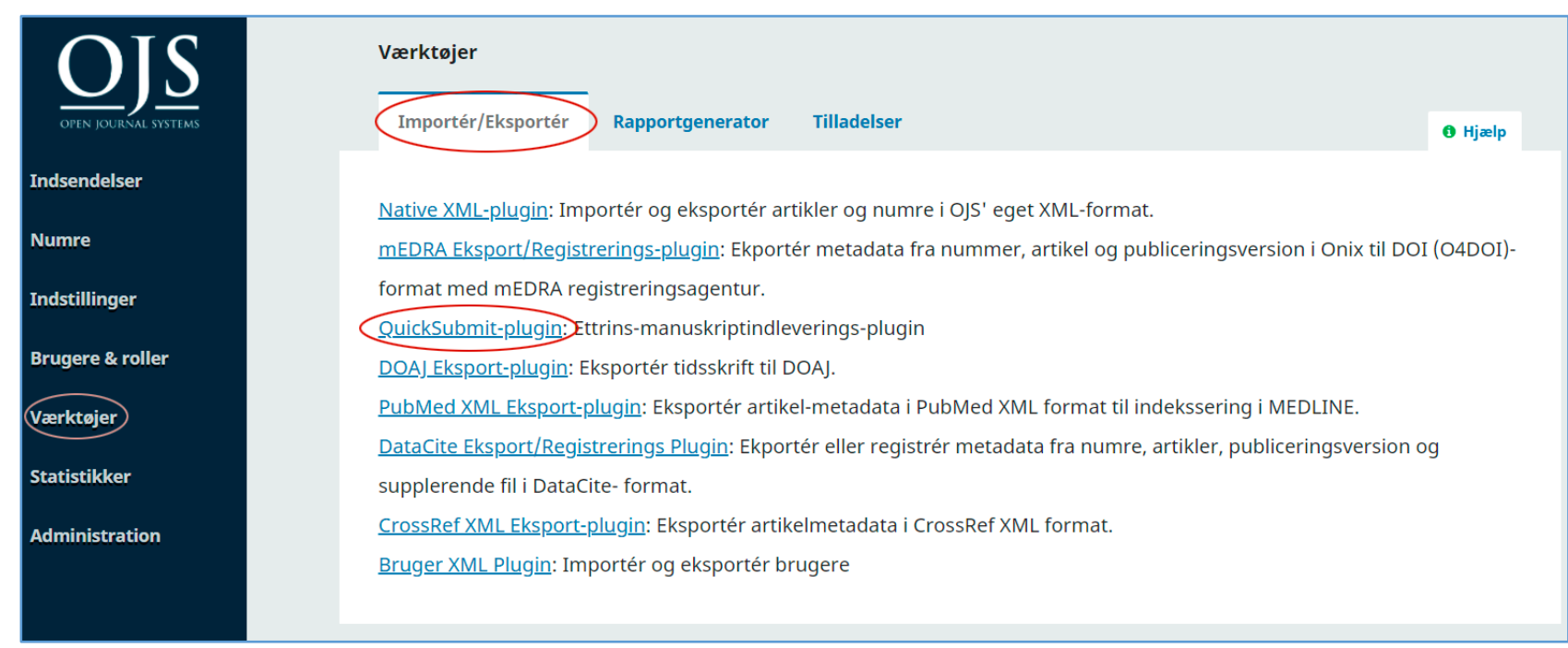

\footnotetext{
${ }^{1}$ Kan også anvendes til 'nye' artikler, hvor publiceringsåret er lig det indeværende år. Her behøver du blot ikke at gå til indsendelsessiden (se senere)
} 
På den fremkomne side udfylder du som minimum de felter, der er markeret med en rød asterisk samt de underliggende sider, der fremkommer ved aktivering af linkene 'Tilføj bidragyder' og 'Tilføj

publiceringsversion' (Se hvordan de underliggende sider udfyldes sidst i denne vejledning, s. 6f)

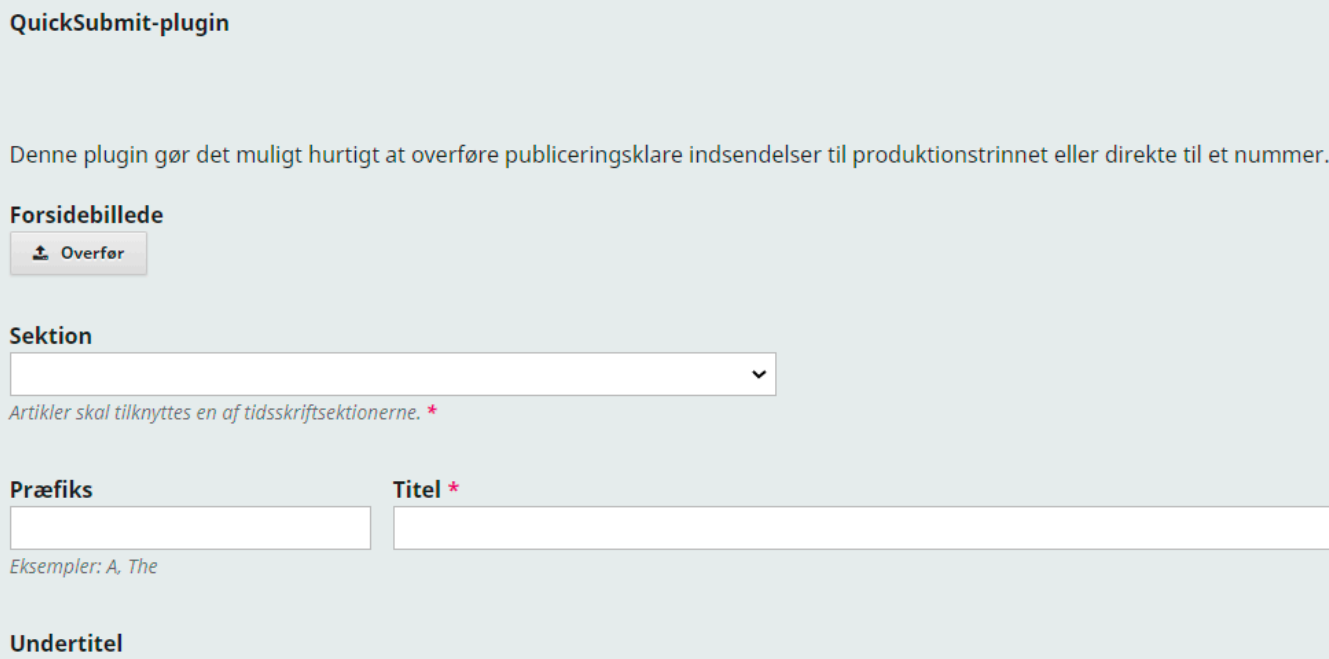


Når alle relevante felter er udfyldt og bidragsydere (forfattere) og publiceringsversion tilføjet, markerer du 'Publiceret'. Derved foldes siden yderligere ud og her udvælger du først, via dropdown-menu, det nummer artiklen skal publiceres i. Dernæst kan du, hvis du ønsker det, indskrive artiklens sidetal. Selvom publiceringsdatoen ikke kommer med over i artiklens metadata, skal dette felt dog stadig udfyldes. Når det er gjort, klikker du på knappen 'Gem'

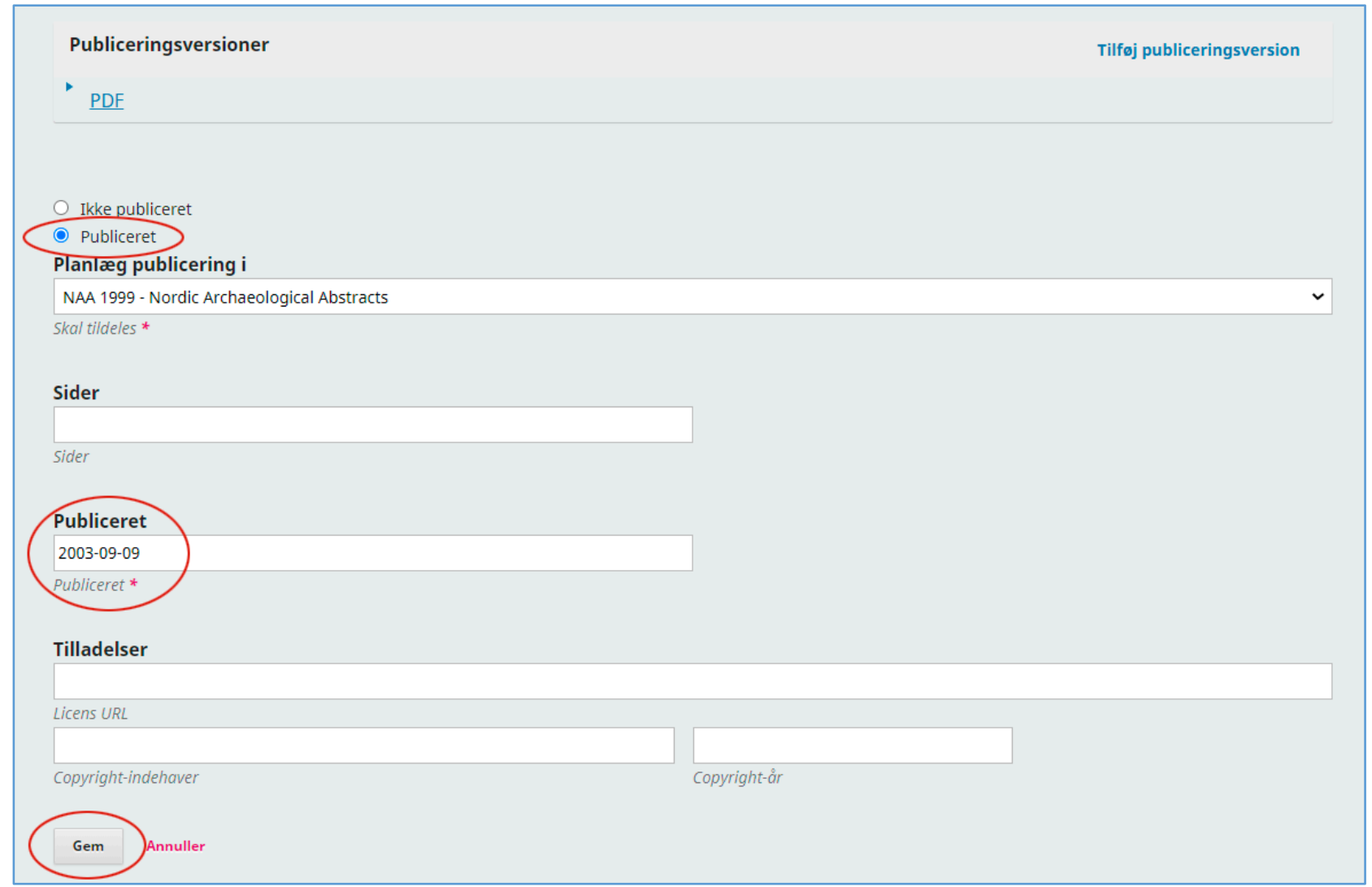

På den efterfølgende side klikker du på linket 'Gå til Indsendelse'2

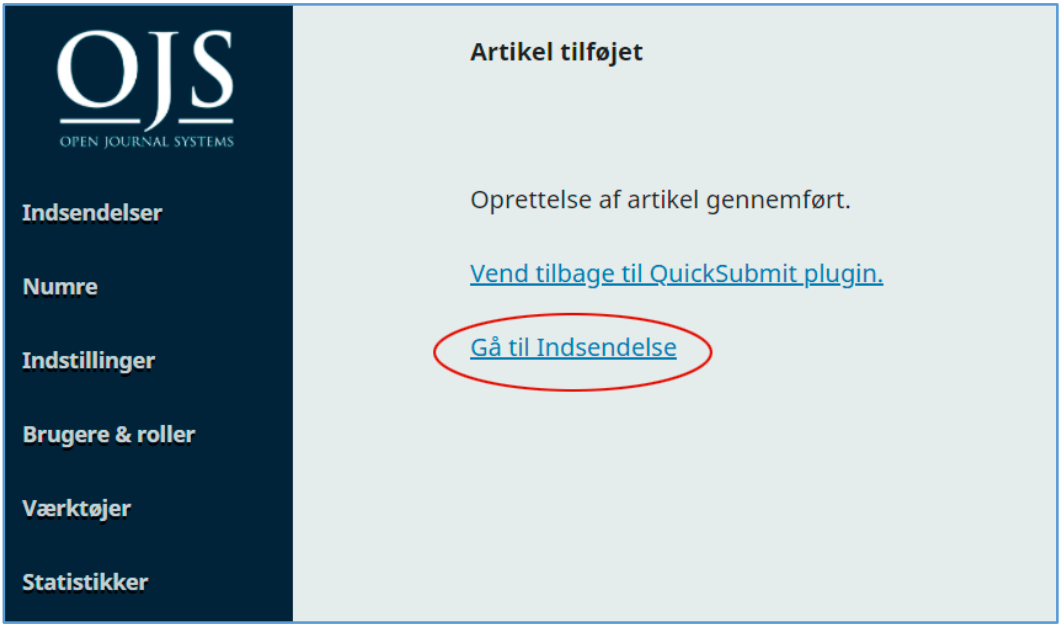
${ }^{2}$ Såfremt publiceringsdatoen passer med dags dato, behøver du - med hensyn til QuickSubmit - ikke at foretage dig
yderligere. Artiklen er lagt i det valgte nummer 
Under 'Indsendelser' vælger du fanebladet 'Publikation' og dernæst linket 'Nummer' i venstre sidemenu. Derved fremkommer nedenstående side og her indskriver du den dato, hvor artiklen først blev publiceret. Klik afslutningsvis på knappen 'Gem'

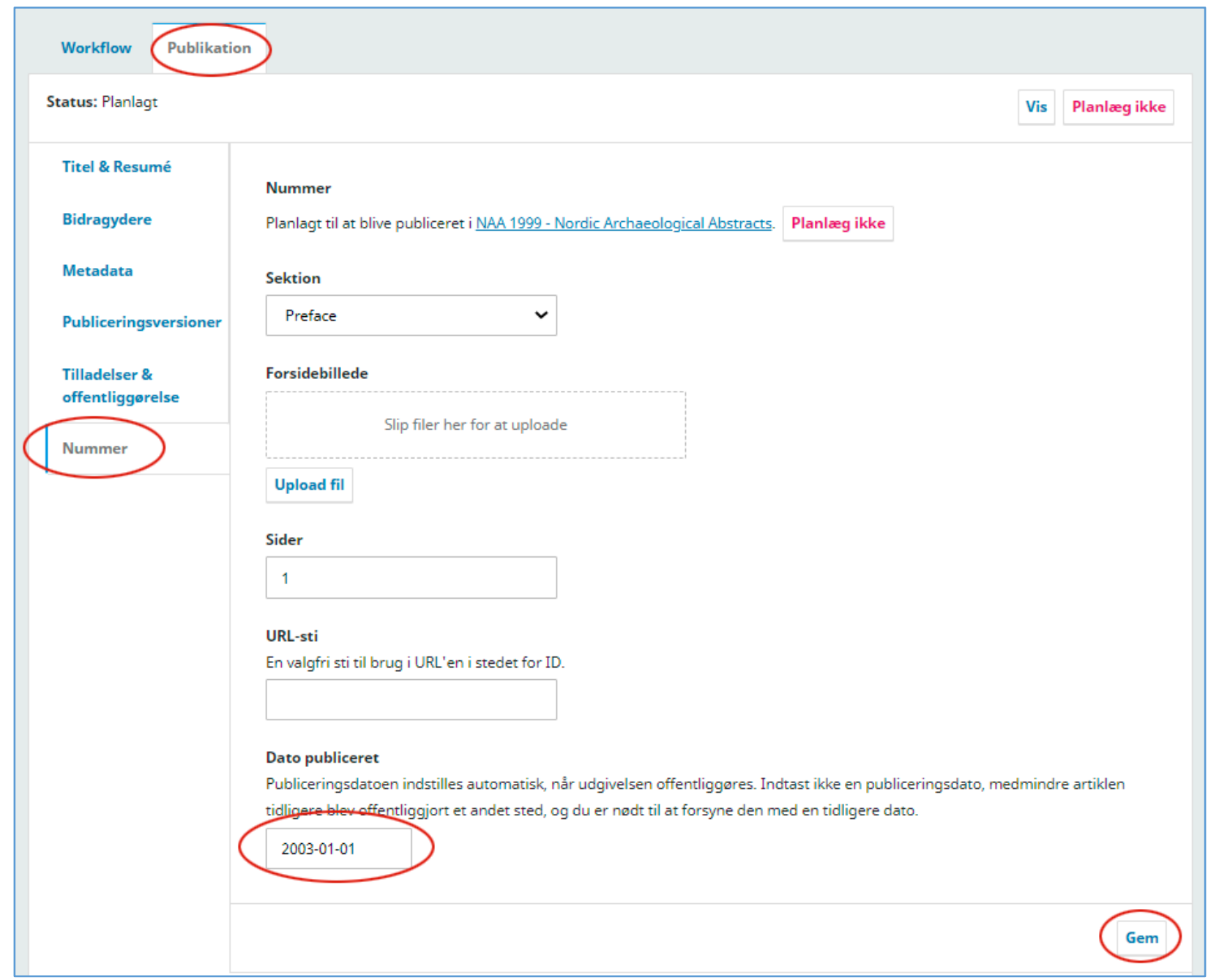

Nu er artiklen blevet lagt i det ønskede nummer med den ønskede publiceringsdato og er klar til publicering.

Hvis du går ind under 'Fremtidige numre' vil du nu se, at nummeret nu indeholder et element

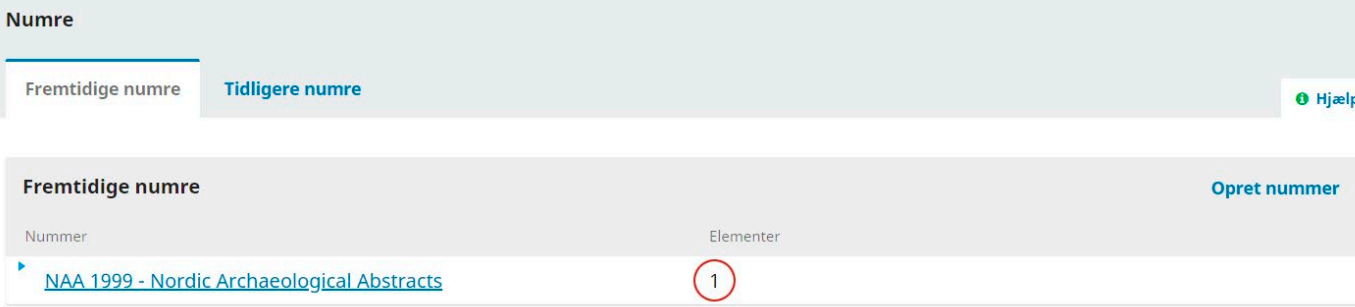


Klikker du på den lille blå pil ud for nummeret og vælger linket 'Vis'....

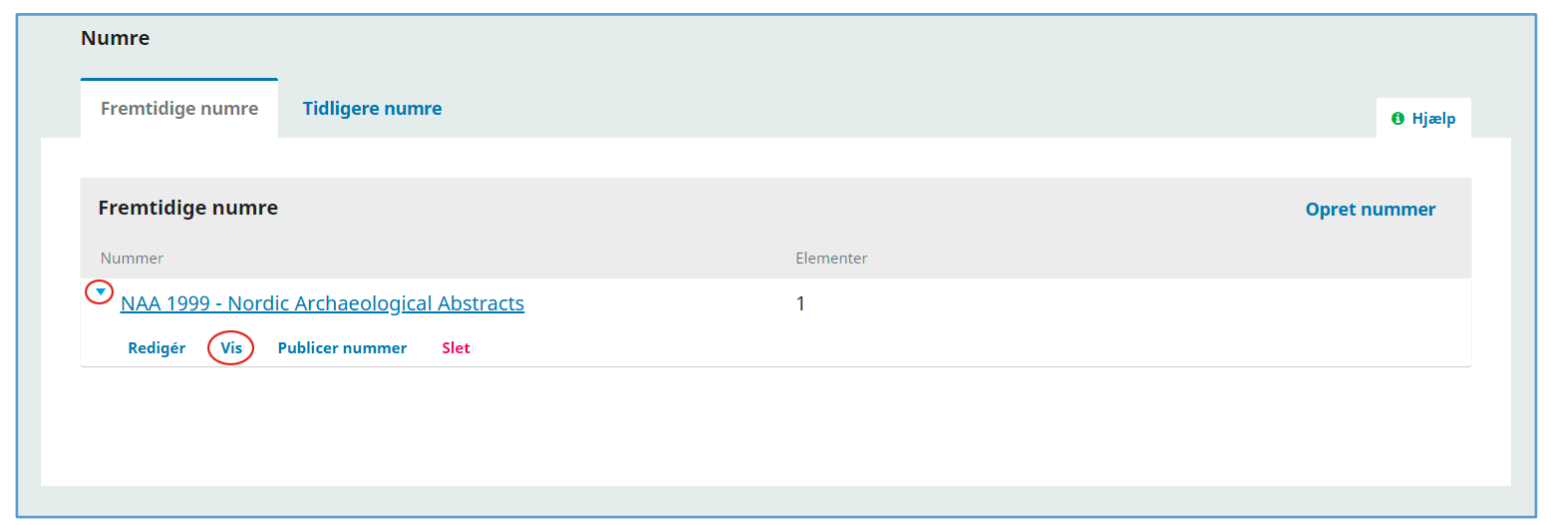

... vil du se en forhåndsvisning af nummeret

\section{Nordic Archaeological Abstracts - NAA}

Nyeste Arkiver Om -

Startside / Arkiver / NAA $1999-$ Nordic Archaeological Abstracts

\section{NAA 1999 - Nordic Archaeological Abstracts}

NAA 1999-Nordic Archaeological Abstracts Preview

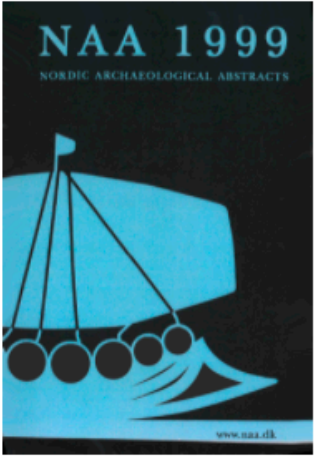

Preface

Preface - NAA 1999

- The Editors

固 PDF (English) 
Underliggende sider - 'Tilføj bidragyder' og 'Tilføj publiceringsversion'

På siden 'Tilføj bidragyder' indskrives artiklens forfatter. Sørg for, som minimum, at alle felter mærket med rød asterisk er udfyldt. Derudover er det også nødvendigt at angive bidragyderens rolle (her 'Forfatter')

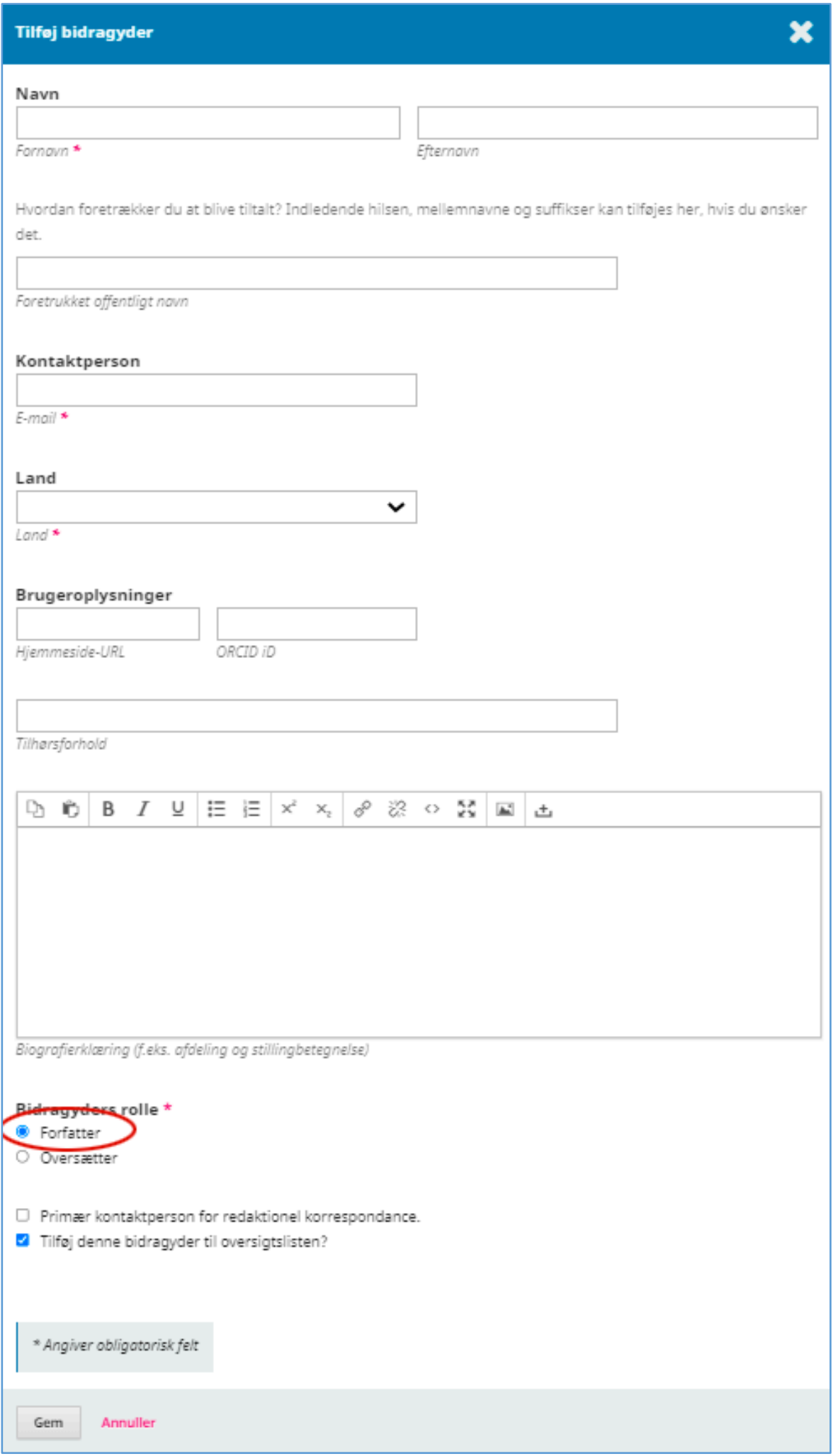


Ved at klikke på linket 'Tilføj publiceringsversion' fremkommer først en side, hvor du skal angive publiceringsformatet (her PDF)

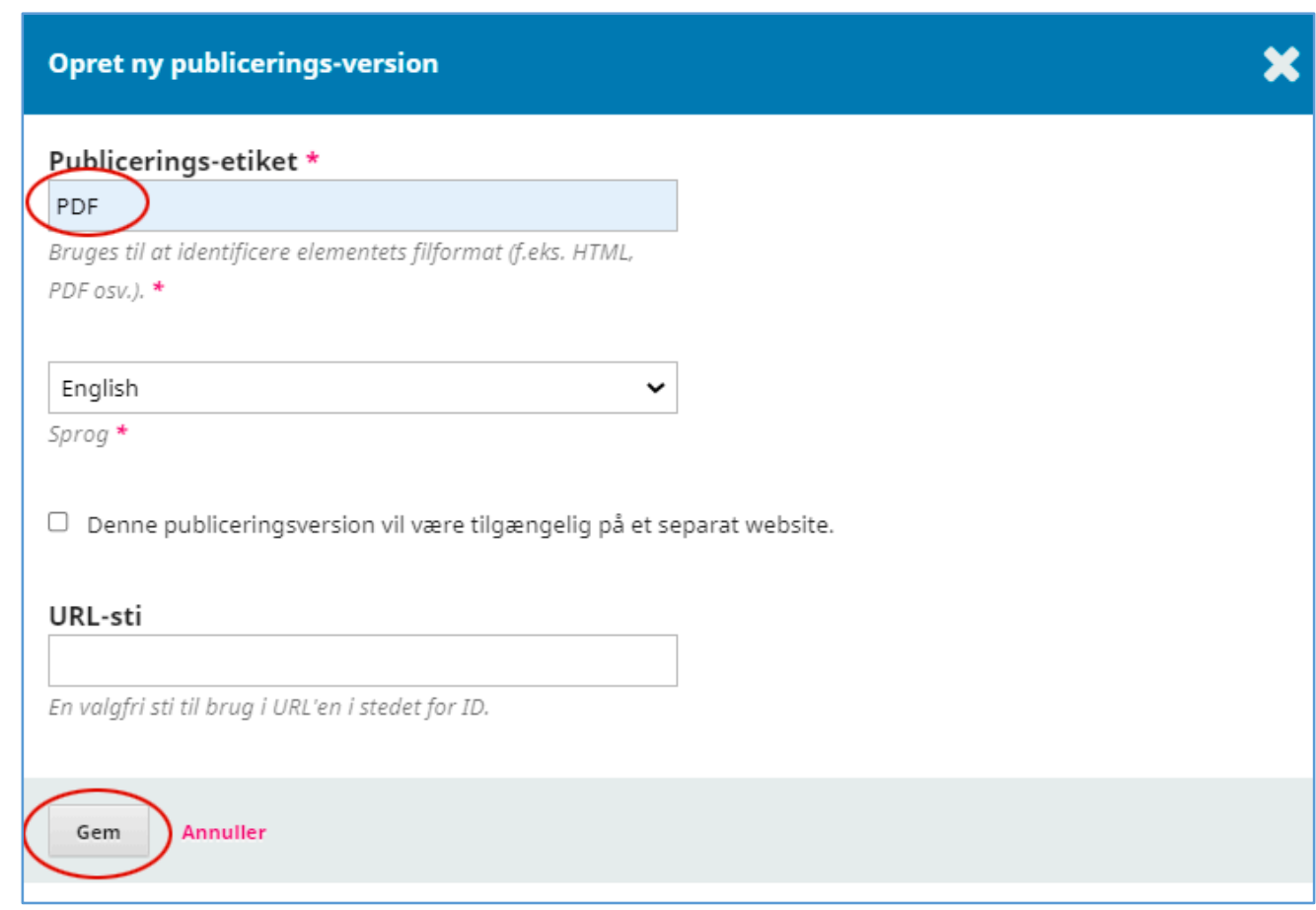

Dernæst skal du vælge artikelmateriale (her 'Artikeltekst')

Upload en publiceringsklar fil
1. Upload fil
2. Gennemse oplysninger
3. Bekræft

\section{Artikelmateriale *}

Artikeltekst

Træk og slip en fil hertil for at påbegynde upload 
Efter at have valgt den relevante fil klikker du 'Fortsæt'

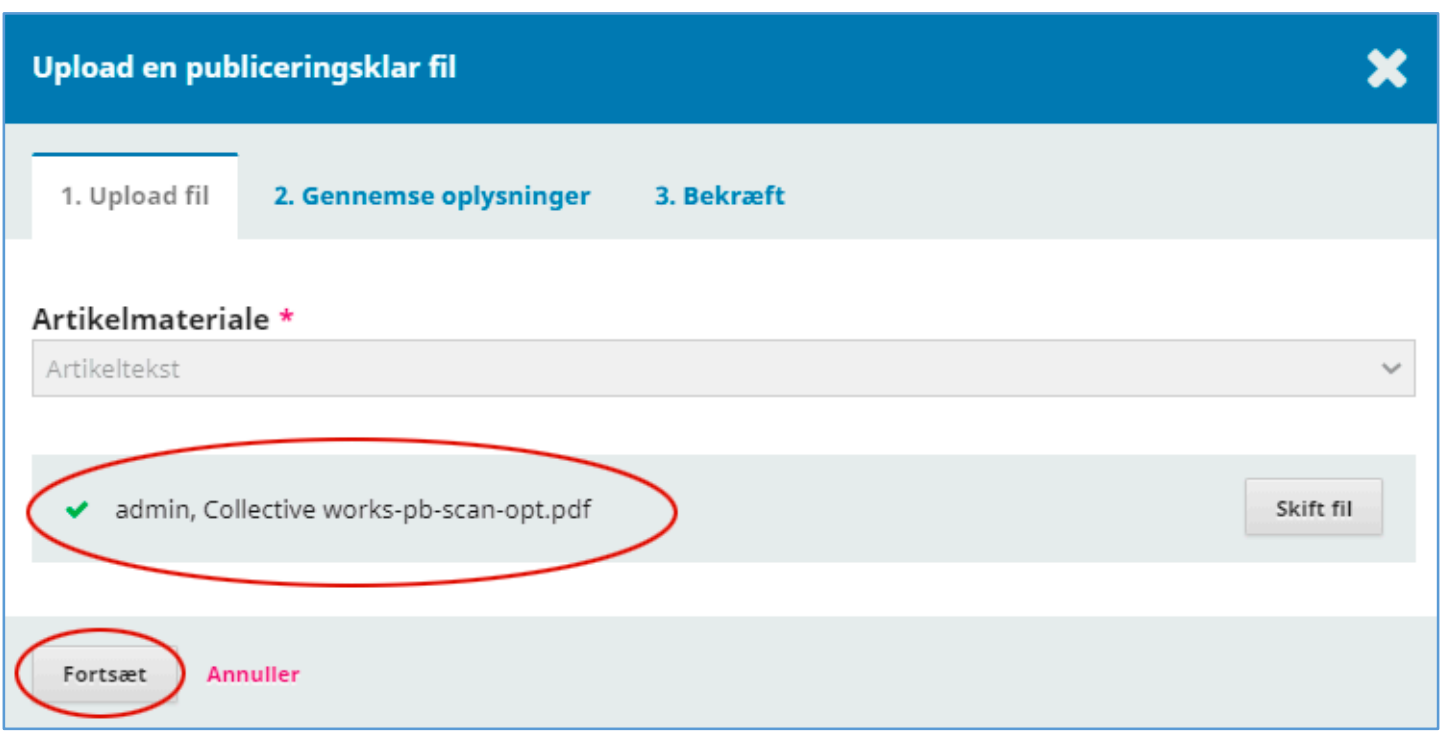

Hvis du ønsker det, kan du her give filen et andet navn ved at klikke på 'Redigér', ellers klikker du bare på 'Fortsæt'

Upload en publiceringsklar fil

1. Upload fil

2. Gennemse oplysninger 3. Bekræft

admin, Collective works-pb-scan-opt.pdf Redigér

母 $\mathrm{pdf} \quad \mathrm{a} 18 \mathrm{~KB}$

Fortsæt Annuller

Så mangler du bare at klikke på 'Udfør'

Upload en publiceringsklar fil

1. Upload fil

2. Gennemse oplysninger

3. Bekræft

Fil tilføjet 
Nu er både bidragyder (forfatter) og publiceringsfil lagt ind og du kan klikke på 'Publiceret'

Ikke publiceret

( ) Publiceret

Planlæg publicering i

Skal tildeles *

Sider

Sider

Se det videre forløb ovenfor (side 3) 